\title{
Tempo de reepitelização corneana com a instilação de colírio contendo hialuronato de sódio e carboximetilcelulose
}

\author{
Corneal reepithelialization time with instillation of eye drops containing sodium hyaluronate \\ and carboxymethylcellulose
}

Luciane Bugman Moreira ${ }^{1}$, Rochelli Scalco ${ }^{2}$, Silvia Hara ${ }^{2}$

\section{RESUMO}

Objetivo: Avaliar o tempo de reepitelização corneana pós abrasão usando colírios comercialmente disponíveis, um contendo hialuronato de sódio a 0,4\%, outro contendo carboximetilcelulose a 1\%, e comparar com a reepitelização sem instilação de colírio. Métodos: Foram utilizados 24 coelhos, nos quais foi feita a abrasão mecânica da córnea nos $8 \mathrm{~mm}$ centrais. Esses animais foram divididos em três grupos. O primeiro grupo recebeu um colírio disponível comercialmente contendo hialuronato de sódio 0,4\%, o segundo recebeu um colírio contendo carboximetilcelulose $1 \%$ e o terceiro não recebeu nenhuma droga. A avaliação foi feita a cada 24 horas por meio da análise de fotografias digitais sob luz azul de cobalto e coramento das córneas com fluoresceína a 2\%. O estudo das imagens foi feito pelo sistema de análise de imagens do Autocad $2009^{\circledR}$. A análise dos dados foi feita comparando o tempo total de reepitelização da córnea e a cada 24 horas entre os três grupos. Resultados: A velocidade de reepitelização do grupo que usou colírio contendo hialuronato de sódio foi em média 90 horas; o grupo que usou carboximetilcelulose apresentou média de 105 horas; e o grupo que não usou nenhum tipo de lubrificante apresentou média de 108 horas para total reepitelização. Houve uma melhor performance na reepitelização após 96 horas nas córneas dos coelhos que usaram os colírios lubrificantes, sendo essa diferença estatisticamente comprovada. Conclusão: O colírio contendo hialuronato de sódio 0,4\% mostrou índice de eficácia maior que aquele contendo carboximetilcelulose 1\%, e este maior eficácia que o controle. Os resultados encontrados neste estudo mostram que o uso de lubrificantes no processo de reepitelização são de extrema valia e devem ser usados de rotina na clínica oftalmológica.

Descritores: Epitélio anterior; Ácido hialurônico; Soluções oftálmicas; Carboximetilcelulose sódica; Animais; Coelhos

\begin{abstract}
Purpose: Evaluate the time of post-abrasion corneal re-epithelialization using commercially available eye drops, one of which containing $0.4 \%$ sodium hialuronate, and the other containing 1\% carboxymethylcellulose, and compare them to the re-epithelialization without the drops.

Methods: 24 rabbits were used, which had the mechanical abrasion of the central $8 \mathrm{~mm}$ of their corneas done. These animals were divided in 3 groups. The first one received the drops containing $0.4 \%$ of sodium hialuronate, the second one received the drops containing 1\% of carboxymethylcellulose and the third group did not receive any drugs. The evaluations took place every 24 hours through the analysis of digital pictures under cobalt blue light and coloring of the corneas with $2 \%$ fluorescein. The pictures were analyzed with the software Autocad 2009 ${ }^{\circledR}$. The data was analyzed through the comparison of the total re-epithelialization time among the three groups

Results: The time of total re-epithelialization of the group using sodium hialuronate was on average 90 hours and the group using carboxymethylcellulose 105 hours, while the group using no drugs was 108 hours. There was a better performance of those groups using the drops and this difference can be proved statistically.

Conclusion: The drops containing $0.4 \%$ of sodium hialuronate showed a higher efficiency rate compared to the drops containing 1\% of carboxymethylcellulose, which was higher than the control group. The results of the present study show that the use of lubricants in the process of re-epithelialization are extremely valid and must be used frequently in ophthalmologic clinic.
\end{abstract}

Keywords: Epithelium, corneal; Hyaluronic acid; Ophthalmic solutions; Carboxymethylcellulose sodium; Animals; Rabbits

\section{INTRODUÇÃO}

A córnea é responsável por 2/3 da refração do olho e para que isso ocorra perfeitamente, sua transparência e forma adequadas são necessárias ${ }^{(1)}$. Para que haja transparência da córnea é preciso que seu epitélio e filme lacrimal estejam íntegros ${ }^{(2,3)}$. O tempo de cicatrização da córnea, na presença de lesão epitelial, pode influenciar em sua transparência e na qualidade óptica resultante ${ }^{(4)}$. A lubrificação ocular também parece ajudar na reepitelização, pessoas com olho seco tendem a ter alterações corneanas e os lubrificantes atuam meIhorando a superfície desse epitélio(5).

Lubrificantes oculares são colírios amplamente usados para diminuir sintomas de corpos estranhos, abrasões corneanas e melhorar o conforto após cirurgias, principalmente refrativas. Eles melhoram o filme lacrimal pré-corneano levando a proteção da superfície ocular que auxilia o processo de reparação celular ocular(6). Existem vários colírios com essa finalidade, entretanto dois deles chamam atenção pelas suas características farmacêuticas. Os colírios a base de hialuronato de sódio (HS) e colírios contendo carboximetilcelulose (CMC).

A comparação entre as duas substâncias tem fundamento bioquímico por terem muitas propriedades semelhantes como a carga iônica, alta microviscosidade e a capacidade de permanecer sobre o epitélio corneano por tempo prolongado(7). E também por estarem envolvidas na recuperação tecidual. Lubrificantes oculares a base de carboximetilcelulose tem sido utilizados com a finalidade de estimular
Submetido para publicação: 18 de julho de 2012

Aceito para publicação: 14 de abril de 2013

Trabalho realizado na Universidade Positivo.

${ }^{1}$ Médica, Universidade Positivo, Curitiba (PR) - Brasil.

2 Estudante, Faculdade de Medicina, Universidade Positivo, Curitiba (PR), Brasil.
Financiamento: Não houve financiamento para este trabalho.

Divulgação de potenciais Conflitos de Interesse: L.B.Moreira, Nenhum; R.Scalco, Nenhum; S.Hara, Nenhum.

Endereço para correspondência: Rochelli Scalco. Travessa Percy Withers, 104/ 50 - Curitiba (PR) 80240-190 - Brasil -E-mail: rochelli_scalco@hotmail.com

Comissão de ética em pesquisa no uso de animais da Universidade Positivo (CEUA - UP). Protocolo CEUA 009/2011. 
a migração celular corneana e diminuir os sintomas de olho seco ${ }^{(5,7)}$. O hialuronato de sódio (HS) atua aumentando a migração celular durante o processo de reeptelização, o que o torna mais rápido. Além disso, ocorre adesão entre o HS e o receptor CD44 nas células, o qual está envolvido em interações célula-célula e célula-substrato que medeiam a migração de células durante a reepitelização ${ }^{(3,8)}$.

O oftalmologista possui várias opções de lubrificantes oculares e muitas vezes há dúvida de qual é o melhor ou qual ajuda realmente na reepitelização corneana. Dessa forma, a comparação entre os lubrificantes oculares mais usados é de grande valia e motivou a realização desse estudo.

O objetivo desse estudo é avaliar o tempo de reepitelização da córnea de coelhos comparando três grupos. Um grupo usando um colírio comercialmente disponível contendo hialuronato de sódio a 0,4\%, outro usando colírio contendo carboximetilcelulose a 1\%, e o terceiro grupo observando a reepitelização natural sem instilação de colírio.

\section{MÉTODOS}

Estudo analítico, experimental, prospectivo e aleatório, conduzido em modelo animal.

Foram utilizados os dois olhos de 24 coelhos brancos da raça Nova Zelândia de ambos os sexos, pesando entre 2,0 e 2,5 Kg. Cuidados com os animais seguiram o regulamento do uso de animais experimentais do Biotério da Universidade Positivo, local onde ficaram durante o experimento, e da "Association for Research in Vision and Ophthalmology".

Foram excluídos do estudo as córneas que adquiriram infecção e tiveram que ser tratadas com antibiótico.

Para a realização das abrasões corneanas, os coelhos foram anestesiados com uma injeção intramuscular de lidocaína (7 mg/kg) e cloridrato de cetamina ( $40 \mathrm{mg} / \mathrm{kg}$ ) e as córneas foram anestesiadas com 1 gota de cloridrato de proparacaína tópica a 0,5\%. Sob luz de uma lupa cirúrgica, retirou-se apenas o epitélio da região central das duas córneas de todos os coelhos por raspagem utilizando lâmina de bisturi número 15 e marcador corneano de 8 mm de diâmetro.

Após o procedimento, foi definida aleatoriamente a separação em três grupos de 8 coelhos cada. Dois grupos receberam 1 gota do medicamento marcado a cada 4 horas em cada olho no período das 8 às 20 horas de cada dia até o término da reepitelização corneana. No grupo 3 , grupo controle, os coelhos passaram pelos mesmos estresses que os demais grupos porém não receberam instilação de lubrificante ocular.

Foram selecionados colírios disponíveis nas farmácias. No grupo 1 foi instilado colírio contendo hialuronato de sódio a 0,4\% (Adaptis fresh ${ }^{\circledR}$ ), enquanto que o grupo 2 recebeu colírio de carboximetilcelulose a 1\% (Adaptis $\left.{ }^{\circledR}\right)$, ambos do laboratório Adapt ${ }^{\circledR}$.

A análise de reepitelização foi realizada através de fotografias a cada 24 horas, sendo a primeira foto imediatamente após a abrasão. Para capturar as fotos foi usada uma câmera fotográfica digital, numa distância de 50 mm, sob luz azul de cobalto e coloração das córneas com fluoresceína a 2\%.

Como sistema de graduação, para quantificar a reepitelização corneal, foram utilizadas medidas planimétricas em $\mathrm{mm}^{2}$ da área de desepitelização. O estudo da área que foi desepitelizada foi feito com o sistema de análise de imagens do Autocad $2009^{\circledR}$ e as áreas foram comparadas perante a proporção porcentual da área desepitelizada. Na fotografia à 0 hora, a área corada com fluoresceína foi determinada como sendo 0\% de área reepitelizada. Quando não havia mais corante de fluoresceína indicava que a área estava totalmente recuperada ou $100 \%$ de reepitelização. Ao final foi comparado o tempo total necessário para recuperação do epitélio corneano nos três grupos.

Para análise estatística, a padronização da amostra foi feita selecionando um olho de cada coelho. Tomou-se como critério de escoIha a área de abrasão inicial mais próxima da planejada inicialmente que era de $50,24 \mathrm{~mm}^{2}$.

Os resultados obtidos no estudo foram descritos por médias, medianas, valores mínimos, valores máximos e desvios padrões. Para a comparação dos grupos em relação às variáveis quantitativas, foi considerado o teste não-paramétrico de Kruskal-Wallis. Para as comparação dos grupos dois a dois foi usada a extensão do teste não paramétrico de Kruskal-Wallis, para teste post-hoc. Para a comparação dos dias de avaliação, dentro de cada grupo, foi considerado o teste não-paramétrico de Friedman. Valores de $p<0,05$ indicaram significância estatística. Os dados foram analisados com o programa computacional Statistica v.8.0.

\section{RESULTADOS}

Na hora zero do estudo, todas as córneas avaliadas possuíam área desepitelizada de tamanho equivalente. A área de ablação no grupo 1 tinha em média 51,66 mm², no grupo 2, em média 50,54 mm² e no grupo 3, 50,18 $\mathrm{mm}^{2}$. Sendo assim, não existe diferença significativa entre os grupos à zero hora $(p=0,833)$.

Os três grupos estudados demonstraram diminuição da área desepitelizada a cada dia com diferença entre a porcentagem de reepitelização nos diferentes momentos do estudo em relação a hora zero (Gráfico 1).

A reepitelização ocorreu de forma similar nas primeiras 72 horas para os três grupos. Após esse período, houve uma tendência a diferença significativa quando os grupos foram comparados às 96 horas $(p=0,075)$. Feito a comparação dois a dois neste momento houve diferença significativa entre os grupos 1 e $3(p=0,049)$ (Tabela 1). Em 120 horas, todas as 8 córneas analisadas do grupo 1 já estavam reepitelizadas, entretanto apenas 6 córneas do grupo 2 e 7 córneas do grupo 3 estavam na mesma situação (Gráfico 2).

Quando se observa o tempo total de reepitelização, o grupo 1 (hialuronato de sódio) apresentou em média 90 horas para reepitelização. O grupo 2 (carboximetilcelulose) apresentou média de 105 horas, já o grupo 3 apresentou média de 108 horas (Tabela 2). Contudo, essas diferenças não foram estatisticamente significantes.

\section{DISCUSSÃO}

Conforme estudo, correlações entre córneas humanas e de coelhos são úteis para avaliação de reepitelização, sendo um modelo confiável e reprodutivo(9).

Para análise estatística dos resultados foi selecionado um olho de cada coelho, pois apesar de termos tratado os dois olhos, eles são interdependentes devido ao metabolismo e alterações sistêmicas, o que pode interferir na reepitelização corneana. O critério de escolha foi o olho que apresentou a área de ablação mais próxima da estipulada inicialmente, deixando a amostra mais homogênea,

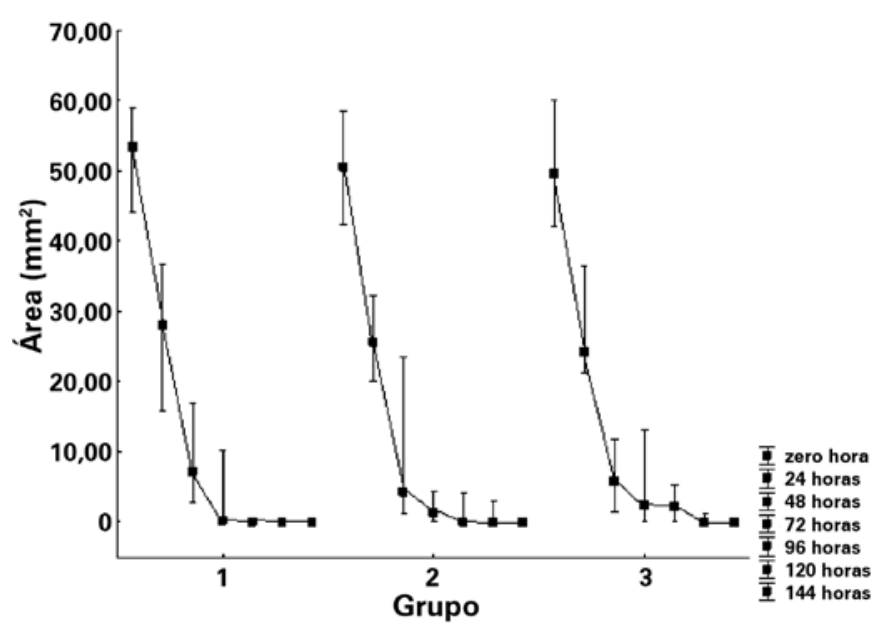

Gráfico 1. Área desepitelizada ao longo do tempo para cada grupo. 
Tabela 1. Área desepitelizada de cada grupo a cada 24 horas

\begin{tabular}{|c|c|c|c|c|c|c|c|c|}
\hline Avaliação & Grupo & $\mathbf{N}$ & Média mm $^{2}$ & Mediana $\mathrm{mm}^{2}$ & Mínimo mm $^{2}$ & Máximo mm² & Desvio padrão & Valor de $p$ \\
\hline \multirow[t]{2}{*}{ Zero hora } & 1 & 8 & 51,66 & 53,35 & 44,11 & 58,91 & 6,02 & \\
\hline & 2 & 8 & 50,54 & 50,56 & 42,30 & 58,47 & 4,77 & \\
\hline \multirow[t]{3}{*}{24 horas } & 1 & 8 & 27,51 & 27,97 & 15,87 & 36,63 & 7,03 & \\
\hline & 2 & 8 & 25,85 & 25,55 & 20,09 & 32,29 & 4,47 & \\
\hline & 3 & 8 & 26,84 & 24,15 & 21,28 & 36,41 & 5,63 & 0,758 \\
\hline \multirow{2}{*}{48 horas } & 2 & 8 & 6,45 & 4,29 & 1,17 & 23,53 & 7,32 & \\
\hline & 3 & 8 & 6,08 & 5,79 & 1,50 & 11,82 & 3,91 & 0,523 \\
\hline \multirow[t]{3}{*}{72 horas } & 1 & 8 & 2,80 & 0,22 & 0 & 10,17 & 3,98 & \\
\hline & 2 & 8 & 1,83 & 1,35 & 0 & 4,28 & 1,54 & \\
\hline & 3 & 8 & 3,96 & 2,44 & 0 & 13,12 & 4,57 & 0,637 \\
\hline \multirow[t]{3}{*}{120 horas } & 1 & 8 & 0 & 0 & 0 & 0 & 0 & \\
\hline & 2 & 8 & 0,74 & 0 & 0 & 3,01 & 1,37 & \\
\hline & 3 & 8 & 0,16 & 0 & 0 & 1,30 & 0,46 & 0,305 \\
\hline \multirow[t]{3}{*}{144 horas } & 1 & 8 & 0 & 0 & 0 & 0 & 0 & \\
\hline & 2 & 8 & 0 & 0 & 0 & 0 & 0 & \\
\hline & 3 & 8 & 0 & 0 & 0 & 0 & 0 & --- \\
\hline
\end{tabular}

*Grupo 1 × grupo 2: $p=0,645 ;$ Grupo 1 x grupo 3: $p=0,0499 ;$ Grupo 2 × grupo 3: $p=0,279 ; N=$ número de elementos; mm² $^{2}$ milímetros quadrados.

Teste não-paramétrico de Kruskal-Wallis, $p<0,05$.

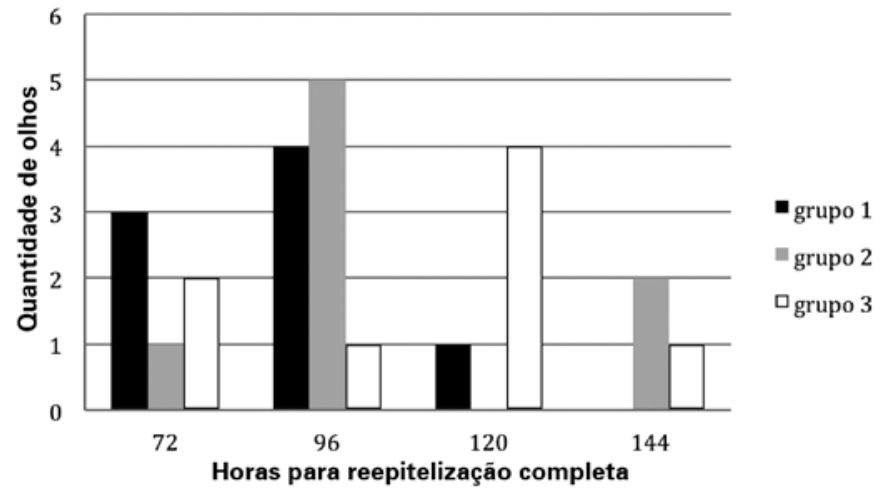

Gráfico 2. Horas de reepitelização dos olhos selecionados.

Tabela 2. Tempo necessário para completa reepitelização

\begin{tabular}{lrrrrrrr}
\hline & \multicolumn{4}{c}{ Tempo necessário para a completa reepitelização } & \\
\cline { 2 - 6 } Grupo & $\mathbf{n}$ & Média & Mediana & Mínimo & Máximo & $\begin{array}{c}\text { Desvio } \\
\text { padrão }\end{array}$ & $\begin{array}{l}\text { Valor } \\
\text { de p* }\end{array}$ \\
\hline 1 & 8 & $90 \mathrm{~h}$ & $96 \mathrm{~h}$ & $72 \mathrm{~h}$ & $120 \mathrm{~h}$ & 16,97 & \\
2 & 8 & $105 \mathrm{~h}$ & $96 \mathrm{~h}$ & $72 \mathrm{~h}$ & $144 \mathrm{~h}$ & 25,45 & \\
3 & 8 & $108 \mathrm{~h}$ & $120 \mathrm{~h}$ & $72 \mathrm{~h}$ & $144 \mathrm{~h}$ & 25,65 & 0,266 \\
\hline
\end{tabular}

$\mathrm{n}=$ número de elementos; $\mathrm{h}=$ horas.

*Teste não-paramétrico de Kruskal-Wallis, $p<0,05$.

pois estudos anteriores mostraram que a reepitelização depende do tamanho da lesão(10,11).
Existem alterações epiteliais provindas da presença de conservantes que acabam por levar algum dano ao processo de reepitelização corneana ${ }^{(4)}$. Os colírios usados neste estudo são formulados contendo conservantes de baixa toxicidade, sendo o sorbato de potássio e o perborato de sódio os conservantes associados ao hialuronato de sódio e ao carboximetilcelulose, respectivamente. Desta forma esse dado não foi levado em consideração, entretanto, futuramente, outros estudos podem ser feitos com colírios sem conservantes.

O tempo de reepitelização total deste estudo - média de 101 horas - foi semelhante a outros sobre o mesmo assunto ${ }^{(4,12)}$.

A afirmação de que o processo de reepitelização da córnea é meIhor sucedido se algum tipo de lubrificante ocular for utilizado durante o evento celular de reparação desse tecido(4) pode ser comprovado neste estudo. Mesmo não tendo diferença estatística, o conhecimento dos valores mostrados na tabela 2 é clinicamente importante, principalmente quando relacionados ao hialuronato de sódio.

O fechamento de uma lesão corneana mais rápida diminui sintomas de dor, lacrimejamento e desconforto, diminui possível infecção e aparecimento de opacidade na região central corneana ${ }^{(13-15)}$. Além disso, em 2006, um estudo sobre transplante de córnea mostrou que cobrir a superfície ocular no final da cirurgia com hialuronato de sódio a 1\% está associado a mais rápida epitelização(10).

Esse mesmo pensamento clínico pode ser usado no que diz respeito a comparação entre os dois colírios estudados. Estatisticamente não houve diferença significativa da mesma forma que outros relatos, os quais afirmam que apesar das propriedades mucoadesivas mais eficientes do HS, este não torna a reepitelização mais rápida ${ }^{(6,16)}$.

Quando foi comparado o resultado de reepitelização a cada dia, observou-se diferença significativa a partir de 96 horas. Desse momento em diante o grupo do hialuronato de sódio teve melhor desempenho com relação aos outros. Sabe-se que o processo de reepitelização possui duas fases, uma inicial mais rápida e outra mais lenta ${ }^{(4)}$. Com 
esses dados acreditamos que é nessa fase que os colírios lubrificantes são mais eficazes e necessários.

\section{CONCLUSÃO}

Houve uma melhor reepitelização após 96 horas nas córneas dos coelhos que usaram o colírio contendo hialuronato de sódio 0,4\% em relação a aquelas aonde não foi utilizado colírio lubrificante.

Os resultados encontrados neste estudo sugerem que o uso de lubrificantes contendo hialuronato de sódio são benéficos no processo de reepitelização e devem ser usados de rotina na clinica oftalmológica.

\section{REFERÊNCIAS}

1. Voughan D. Oftalmologia Geral. 4a ed. São Paulo: Ateneu; 1997.

2. Mello GR. Avaliação da neovascularização e da reepitelização da córnea com uso do bevacizumabe subconjuntival estudo experimental em coelhos [Dissertação] Curitiba: Faculdade Evangélica do Paraná; 2009.

3. Gomes JA, Amankwah R, Powell-Richards SA, Dua HS. Sodium hyaluronate (hyaluronic acid) promotes migration of human corneal epithelial cells in vitro. $\mathrm{Br} J$ Ophthalmol. 2004;88(6):821-5.

4. Moreira L. Reepitelização corneana após ablasão com excimer laser utilizando fluoroquinolona [Dissertação]. Curitiba: Universidade Federal do Paraná; 2002.

5. Bruix A, Adan A, Casaroli-Marano RP. Efficacy of sodium carboxymetheylcellulose in the treatment of dry eye syndrome. Arch Soc Esp Oftalmol [internet]. 2006 [cited 2010 Mar 17];81:85-92. Available from: http://www.oftalmo.com/seo/archivos/ maquetas/9/0C20F412-29A4-EA48-FB1F-000033A81E99/articulo.pdf
6. Aragona P, Papa V, Micali A, Santocono M, Milazzo G. Long term treatment with sodium hyaluronate-containig artificial tears reduces ocular surface damage in patients with dry eye. Br J Ophthalmol. 2002;86(2):181-4

7. Garrett Q, Simmons PA, Xu S, Vehige J, Zhao Z, Ehrmann K, et al. Carboxymethylcellulose binds to human corneal epithelial cells and is a modulator of corneal epithelial wound healing. Invest Ophthalmol Vis Sci [Internet]. 2007 [cited 2010 Jun 26];84(4):1559-67. Available from: http://www.iovs.org/content/48/4/1559.full.pdf+html

8. Yu FX, Guo J, Zhang Q. Expression and distribution of adhesion molecule CD44 in healing corneal epithelia. Invest Ophthalmol Vis Sci. 1998;39(5):710-7.

9. Hirst LA, Kenyon KR, Fogle JA, Hanninen L, Stark WJ. Comparative studies of corneal surface injury in the monkey and rabbit. Arch Ophthalmol. 1981;99:1066-73. 10. Borderie VM, Touzeau O, Bourcier T, Allouch C, Laroche L. Graft reepithelialization after penetrating keratoplasty using organ-cultured donor tissue. Ophthalmology. 2006; 113(12):2181-6

11. Chéour M, Nasri H, Kamoun H, Lamloum H, Kasri A, Hamdi S, Kraiem A. [Factors associated with graft reepithelialization after penetrating keratoplasty]. J Fr Ophthalmol. 2008;31(8):786-9. French.

12. Detorkis ET, Siganos DS, Kozobolis VP, Pallikaris IG. Corneal epithelial wound healing after excimer laser photorefractive and photoastigmatic keratectomy (PRK and PARK). Cornea. 1999;18(1):25-8

13. Wu WC, Stark WJ, Green WR. Corneal wound healing after 193-nm excimer laser keratectomy. Arch Ophthalmol. 1991:109(10):1426-32.

14. Gipson IK. Adhesive mechanisms of the corneal epithelium. Acta Ophthalmol Suppl. 1992;(202):13-7

15. Figueiredo ES, Macedo AC, Figueiredo PF, Figueiredo SR. Aplicações oftalmológicas do ácido hialurônico. Arq Bras Oftalmol. 2010;73(1):92-5.

16. Condon PI, McEven CG, Wright M, Mackintosh G, Prescott RJ, McDonald C. Double blind, randomised, placebo controlled, crossover, multicentre study to determine the efficacy of $0.1 \%(\mathrm{w} / \mathrm{v})$ sodium hyaluronate solution (Fermavisc) in the treatment of dry eye syndrome. Br J Ophthalmol [Internet]. 1999 [cited 2010 Jun 21] 83(10):1121-4. Available from: http://www.ncbi.nlm.nih.gov/pmc/articles/PMC1722832/?tool=pubmed

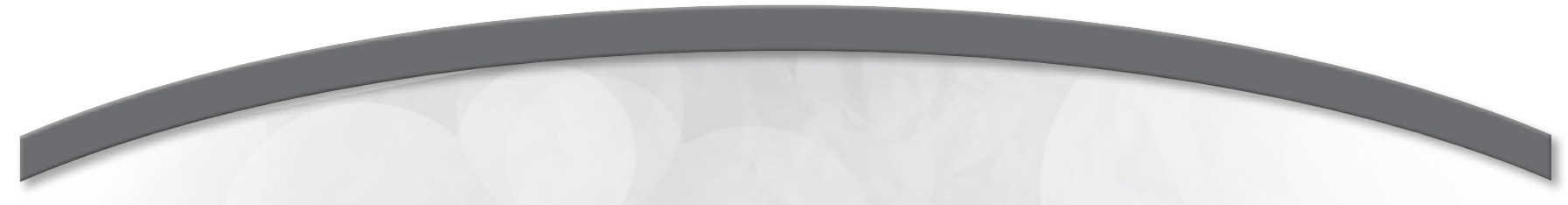

$39^{\circ}$ Congresso da Sociedade Brasileira de Retina e Vítreo

\author{
10 a 12 de abril de 2014
}

Royal Palm Plaza

Campinas (SP)

Informações:

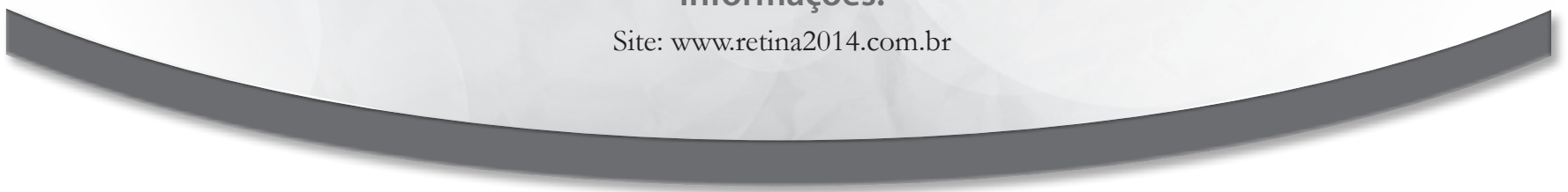

